\title{
Development of Sustainable and Eco-Friendly Materials from Termite Hill Soil Stabilized with Cement for Low-Cost Housing in Chad
}

\author{
Assia Aboubakar Mahamat ${ }^{1, *(1)}$, Numfor Linda Bih ${ }^{1}{ }^{(0}$, Olugbenga Ayeni $^{1}{ }^{1}$, Peter Azikiwe Onwualu ${ }^{1}(\mathbb{D}$, \\ Holmer Savastano Jr. ${ }^{2}$ (i) and Winston Oluwole Soboyejo ${ }^{3}$
}

check for

updates

Citation: Mahamat, A.A.; Linda Bih, N.; Ayeni, O.; Azikiwe Onwualu, P.; Savastano, H., Jr.; Oluwole Soboyejo, W. Development of Sustainable and Eco-Friendly Materials from Termite Hill Soil Stabilized with Cement for Low-Cost Housing in Chad. Buildings 2021, 11, 86. https://doi.org/ 10.3390 /buildings 11030086

Academic Editor: Marco Di Ludovico

Received: 5 January 2021

Accepted: 2 February 2021

Published: 26 February 2021

Publisher's Note: MDPI stays neutral with regard to jurisdictional claims in published maps and institutional affiliations.

Copyright: (c) 2021 by the authors. Licensee MDPI, Basel, Switzerland. This article is an open access article distributed under the terms and conditions of the Creative Commons Attribution (CC BY) license (https:// creativecommons.org/licenses/by/ $4.0 /)$.
1 Department of Materials Science and Engineering, African University of Science and Technology, Abuja, Federal Capital Territory 900100, Nigeria; nlinda@aust.edu.ng (N.L.B.); oayeni@aust.edu.ng (O.A.); aonwualu@aust.edu.ng (P.A.O.)

2 Department of Biosystems Engineering, Research Nucleus on Materials for Biosystems NAP BioSMat, University of Sao Paulo, Pirassununga 13635-900, Sao Paulo, Brazil; holmersj@usp.br

3 Department of Mechanical Engineering, Worcester Polytechnic Institute, Worcester, MA 01609, USA; wsoboyejo@wpi.edu

* Correspondence: aassia@aust.edu.ng

\begin{abstract}
This paper explores the effects of cement stabilization (5, 10, 15 and $20 \mathrm{wt} \%)$ on the structural and mechanical properties (compressive/flexural strengths and fracture toughness) of abandoned termite mound soil. The crystal structures and crystallinity of the constituents were determined using X-ray diffraction (XRD), while the microstructure was characterized via scanning electron microscopy (SEM) and energy dispersive X-ray spectroscopy (EDS). The functional groups were also identified using Fourier transform infra-red spectroscopy (FTIR). The compressive/flexural strengths of the stabilized and un-stabilized termite mound soil were also studied after curing for 7 , 14 and 28 days. The fracture toughness mechanism was analyzed with the aid of the R-curve method. Additionally, the underlying deformation and cracking mechanisms are elucidated via in-situ/ex-situ optical and scanning electron microscopy. The stabilized termite mound soil displayed the highest mechanical properties of $13.91 \mathrm{MPa}, 10.25 \mathrm{MPa}$ and $3.52 \mathrm{kPa} \cdot \mathrm{m}^{1 / 2}$ for compressive strength, flexural strength and fracture toughness, respectively. Besides displaying good mechanical properties and being locally available at no cost, renewable and an eco-friendly material, the termite mound soil will contribute to lowering the cost of housing in Sub-Saharan Africa, particularly in Chad.
\end{abstract}

Keywords: cement stabilization; termite mound soil; structure; compressive/flexural strengths; fracture toughness; deformation and fracture mechanisms

\section{Introduction}

In the last decades, the construction field is facing major concerns about the carbon emissions associated with production of cement which is typically used for construction of buildings across the world [1]. Since these emissions are responsible for about $7 \%$ of global $\mathrm{CO}_{2}$ emissions $[2,3]$, there is a need to explore alternative building materials that will reduce the overall amount of $\mathrm{CO}_{2}$ emissions. This has stimulated significant research efforts into alternative building materials $[4,5]$ that can reduce the overall use of cement in buildings [1,6]. Within this context, earth-based materials are "green" materials that can reduce the carbon emissions [7] that are associated with the construction of buildings. Compared to conventional cement-based [8] building materials [9], earth-based materials are cheap [10], environmental-friendly [11,12] and available [13] globally. They can also have attractive combinations of mechanical properties $[14,15]$ while consuming lower amounts of energy during their production [16,17]. However, according to estimates by UN-Habitat, approximately 238 million people lived in slums or informal settlements in Sub-Saharan Africa (SSA) in 2018 [18]. These slums are generally considered to be sub-standard housing. 
They also contribute to low-life expectancy, poor heath indices and low indices of wellbeing because housing is a major fundamental need for human being and constitutes the main factor for its survival and its development. Therefore, adequate housing contributes to physical development, moral health and social stabilization. All these factors affect immensely individual ability and productivity, thus the low productivity of SSA. In SSA, some countries have easy access to conventional building materials as is the case of Nigeria compared to others SSA countries, for instance Chad. In Nigeria, the construction industry is directed towards development of sustainable materials from wastes $[5,13]$ and earthbased [19] and recycled materials [12] through environmental-friendly technologies [6]. In Chad, transformation of local materials into sustainable construction materials have not been promoted, hence the region's dependence on cement. Despite that, Chad's access to conventional building materials is problematic because of geographical constraints and scarcity of manufacturing industries. In fact, in Chad, construction materials are principally imported from Nigeria as the few local manufacturing industries are not reliable [20,21]; consequently, these imported materials are very expensive. In addition, the construction field is dependent on the borders movement as it witnesses shortages that paralyze this field. Chad is one of the central African countries that has experienced massive growth of slums with immense decrease of productivity in the last decades. In Chad, the gross domestic product is estimated at 728 USD per citizen and the general debt rate is evaluated at 334 USD per citizen [22], for a population of 15 million in 2018. Additionally, from the World Bank report an adult in Chad is $71 \%$ less productive than a person benefiting from appropriate basic needs services [23] (health, housing and education). It is noteworthy that the cost of a standard house is about 1000 USD per $\mathrm{m}^{2}$ [24]. From those statistics, affording an adequate house is really difficult for a low-income citizen, but in reality, it is almost impossible. Henceforth, a first step of addressing the problem of housing in Chad can be the partial replacement of cement with natural pozzolanas or similar in the production of blocks. This could solve the challenge of cost, however, the challenges related to the brittle failure can be addressed by addition of natural fibers as reinforcement. In most cases, the structural applications of earth-based materials [11] require the use of cement as a stabilizer [25] or reinforcement with natural [26]/synthetic [27] fibers. In any case, the underlying strengthening and toughening mechanisms associated with the stabilization of earth-based materials have not been studied using the mechanistic approaches that have been applied to the study of natural fiber-reinforced earth-based composites [15]. Termite hills are classified as earth-based materials, they are very abundant in Chad but do not serve any economic value, so they are often demolished. In contrast, our basic understanding of termite hill soil composition, formation and bonding is still very limited. Termite hill soil or (termite mound soil, TMS) is obtained from termite hills that are produced by mound-building termites [28]. Termites are the dominant species in the tropical ecosystem, where they constitute up to $95 \%$ of the total quantity of soil insect in the ecosystem. They are considered as "ecosystem engineers" because they bind the soil with their secretions (saliva) to produce complex and robust termite mounds. They also egest and excrete organic matter and elements such as phosphorus, potassium, magnesium and nitrogen, which can be mixed with the soil for applications in agriculture [29]. Hence, termite mound soils contain relatively high contents of organic matter. Their relatively high $\mathrm{pH}$ values also increase their ability to mix with nearby soils. Furthermore, the guts of termites have been shown to contain compartments that present rising gradients of $\mathrm{pH}$ and different status of oxygen and hydrogen [30], which may contribute ultimately to the chemistry and structure of termite mound soils. In any case, the resulting termite mounds contain soils with clay contents that are $20 \%$ greater than those in nearby soils [28].

Prior work by Elinwa [31] has explored the potential to use termite mound soils as pozzolanic materials in mixtures of calcined ant mound clay and cement mortar. Their work explored the effects of ant mound clay on the hydration process (in cement), as well as the resulting compressive strength, and its repercussions for the flexural and splitting tensile strength. They concluded that their ant mound clay was a weak pozzolanic material. 
Previous work reported that termite mound clay is a better molding material than ordinary clay [32]. The improvements in the molding characteristics of the termite mound soil were attributed to the effects of saliva secretions (from termites) during the construction of termite mounds. Minjinyawa et al. [30] have also shown that termite mounds have good resistance to erosion, abrasion and penetrations of liquids, compared to ordinary clay. Other researchers have also suggested that the improved mechanical properties of TMS (compared to those of nearby soils) can be attributed to the effects of termite secretions [32]. Researchers have suggested that termites can also have a significant effect on nutrient cycling and the renewal of mineral soil [33]. Gandia et al. [29] have also studied the effects of mixing synthetic termite saliva with adobe. The resulting materials exhibited a modest increase in the bulk densities of adobe with mixtures of saliva. Synthetic termite saliva products have emerged from prior studies on TMS [34]; they play the role of stabilizer due to the formation of organo-mineral compounds (that are present in the soil) that bind clay particles together. The products obtained from termite saliva are also ecologically sustainable, hydrophobic, water soluble, resistant to oxidation, resistant to microorganisms, applicable as low viscosity and cost efficient [35]. Subsequently, termite mound soil presents the characteristic of a sustainable and renewable alternative to conventional building materials except for the few problems that can be solved through stabilization among other techniques. From the American Society for Testing and Materials (ASTM), stabilization is a technique to increase the soil strength by enhancing its load-bearing capacity, improving its permeability and resistance and solving swelling and damping problems [36]. Boga et al. carried out studies on the spatial distribution and density of termites in an artificial botanic forest. They found out that over 26 termites' mounds were inactive out of 165 mounds [37]. Based on these results, it can be deducted that the quantity of inactive termite mounds may be higher in the natural environment.

In any case, our current understanding of the effects of stabilizers on strength and fracture behavior of termite mound soils is limited. Therefore, the current study will explore the effects of cement stabilizers [38] on the strength and fracture toughness of controlled mixtures of termite mound soil and cement. This study is a first in terms of examining the fracture mechanism in soil-based termite mound mixtures. It is anticipated that the partial replacement of cement with termite mound soil could reduce the effective cost of building materials that are used in sustainable construction. It could also reduce the overall gas emissions associated with the production of mortars that are used for the stabilization of earth-based materials. It is noteworthy to recall that in this study abandoned (or inactive termites') mounds have been used.

This paper is divided into 4 sections. Following the introduction in part 1, the materials that are used are presented in Section 2, along with the experimental proce-dures. The related theory is then presented with the structure and mechanical proper-ties in Section 3. Salient conclusions arising from this study are then presented in Section 4.

\section{Materials and Methods}

\subsection{Materials}

The termite mound soil that was used in this study was collected from mounds in N'djamena, Chad. The particle sizes of the soils extracted from the 10-15-year-old deserted mounds were determined via sieving in accordance with the British Standard BS 1377:2 code [39]. This revealed that $85 \%$ of particles were finer than $800 \mu \mathrm{m}$. Atterberg limits for the termite mound soil were determined in accordance with BS 1377:2. The moisture content of the termite mound soil was also determined in accordance with BS 1377:2, while the specific gravity was determined using the ASTM D854-14 code [40]. Energy dispersive spectroscopy (EDX) was used to obtain semi-quantitative estimates of the chemical compositions of the Termite Mound Soil (TMS) during scanning electron microscopy (SEM). This was done using a Carl Zeiss scanning electron microscope that was instrumented with a Model EVO LS10 EDX system (Carl Zeiss, Pleasanton, CA, USA). The physical properties and the chemical composition of the TMS are summarized in Table 1. 
Table 1. Termite mound soil physical and chemical characteristics.

\begin{tabular}{cc}
\hline \multicolumn{2}{c}{ Physical Properties } \\
\hline Particle size distribution & $85 \%$ smaller than $800 \mu \mathrm{m}$ \\
Moisture content & $3.85 \%$ \\
Specific gravity & 2.60 \\
Dry density & $0.458 \mathrm{~g} / \mathrm{cm}^{3}$ \\
Optimum moisture content & $15 \%$ \\
Liquid limit & $35.17 \%$ \\
Plastic limit & $20.80 \%$ \\
Plasticity index & $14.37 \%$ \\
\hline $\mathrm{Chemical} \mathrm{Composition} \mathrm{(main} \mathrm{elements} \mathrm{only)} \mathrm{wt. \%}^{\mathbf{w}} \%$ & 19.376 \\
$\mathrm{SiO}_{2}$ & 9.154 \\
$\mathrm{Al}_{2} \mathrm{O}_{3}$ & 7.534 \\
$\mathrm{Fe}_{3} \mathrm{O}_{4}$ & 1.865 \\
$\mathrm{~K}_{2} \mathrm{O}$ &
\end{tabular}

Portland cement produced by Dangote Portland Limestone Cement Industry (Abuja, Nigeria) from their depot at the Federal Capital Territory, Nigeria. The Portland cement was used as a stabilizer in this study. The cement used is the Portland cement type I following the ASTM requirements for general construction purpose [41] with fairly high tricalcium silicate $C_{3} S$. The ordinary Portland cement contains about $75 \mathrm{wt} \%$ of calcium silicate minerals with fine particles of $70 \mu \mathrm{m}$ according to the supplier.

In the sample preparation order, TMS/cement mixtures with $0,5,10,15$ and $20 \mathrm{wt} \%$ of Portland cement were mixed in a laboratory mixer for 5-10 $\mathrm{min}$ before addition of water. The resulting mixtures were then poured into metallic cubic molds with dimensions of 50 $\mathrm{mm} \times 50 \mathrm{~mm} \times 50 \mathrm{~mm}$ for the fabrication of compression testing, whereas molds with dimensions of $200 \mathrm{~mm} \times 100 \mathrm{~mm} \times 50 \mathrm{~mm}$ were used for bend specimens or determination of flexural strengths. For the determination of fracture toughness, molds with dimensions of $200 \mathrm{~mm} \times 100 \mathrm{~mm} \times 50 \mathrm{~mm}$ with single edge notch were used. The specimens were cured at room temperature $\left(27^{\circ} \mathrm{C}\right)$ for 7,14 and 28 days before testing, and a minimum of 3 samples were produced for each formulation for each testing. All the mix designs were produced under the same conditions, but not on the same day.

\subsection{Material Characterization}

X-ray diffraction (XRD) was used to determine the crystal structures of the minerals that were present in the mixtures of TMS at the different replacement level of Portland cement. This was done using a Thermo Scientific X-ray Fluorescence (XRF) Epsilon Spectrometer (model ARL quant'x XRD, Rotkreuz, Switzerland) that was operated within a $2 \theta$ range of $3-65^{\circ}$, a wavelength of $1.5406 \AA$ and an angular velocity of $3 \% / \mathrm{min}$. The XRD samples were prepared by grinding the TMS and the mixture (with a pestle and a mortar) to a fine homogeneous powder. The ground powder was poured onto an aluminum specimen holder prior to XRD analysis.

A Thermo Scientific Nicolet iS5 FTIR system (Thermo Scientific Nicolet, Worcester, MS, USA) was used for the characterization of bonds that were present in the powder mixtures of TMS and Portland cement with volume ratios of 100:0, 95:5, 90:10, 85:15 and 80:20. Prior to FTIR analysis, the different mixtures were blended with potassium bromate $(\mathrm{KBr})$ in a ratio of 5:1. This was done in a ceramic mold before compacting the mixed powders to form pellets that were placed on specimen holders for the FTIR analysis.

SEM was used to characterize the cured microstructures of the TMS and Portland cement structures. This was done using a Carl Zeiss Model EVO LS10 (Carl Zeiss, Pleasanton, CA, USA) that was instrumented with an EDX system that can detect elements between sodium $(\mathrm{Na}, \mathrm{Z}=11)$ and uranium $(\mathrm{U}, \mathrm{Z}=92)$ with high resolution. Prior to SEM imaging, the samples were embedded in $\mathrm{z}$ silver containing a polymer/metal mixture, ground, polished and coated with gold, to facilitate the imaging of the surfaces using SEM. 


\subsection{Mechanical Properties Measurements}

For the compression deformation, compressive strength testing was carried out on the specimens for each composition of TMS and Portland cement with volume ratios of 100:0, 95:5, 90:10, 85:15 and 80:20. Three samples were produced for each composition and were cured at room temperature $\left(27^{\circ} \mathrm{C}\right)$ for 7,14 and 28 days, prior to mechanical testing. The specimens were then loaded monotonically in an electromechanical testing machine UTM7001 Model 4002 (Utest, Ankara, Turkey) at a loading rate of $1.2 \mathrm{kN} / \mathrm{s}$. Prior to testing, the actual dimensions of the specimens were measured using Vernier calipers. The compressive strengths were thus obtained from the following expression:

$$
\sigma c=\frac{F i}{A i}
$$

where $\sigma c$ is the compressive strength in megapascal (MPa), $F i$ is the force at the onset of failure in newton $(\mathrm{N})$ and $A i$ is the initial cross-sectional area in millimetre square $\left(\mathrm{mm}^{2}\right)$.

The flexural tests were conducted on specimens of $200 \mathrm{~mm} \times 100 \mathrm{~mm} \times 50 \mathrm{~mm}$; for each formulation three samples were produced and cured in the laboratory environment at room temperature $\left(27^{\circ} \mathrm{C}\right)$ for 7,14 and 28 days. Hence, a total number of 45 specimens were produced for the flexural tests. The specimens were subjected to the same conditions before being loaded under a three-point bending regime in a hydraulic universal testing machine UTM7001 Model 4002 (Utest, Ankara, Turkey) at a loading rate of $1.2 \mathrm{KN} / \mathrm{s}$. The flexural strength was calculated from the following equation:

$$
\sigma f=\frac{3 F L}{b d^{2}}
$$

where $\sigma f$ is the flexural strength in $\mathrm{MPa}, F$ is the load at the onset of failure in $\mathrm{N}, L$ is the distance between the support points in $\mathrm{m}, b$ is the breadth in $\mathrm{m}$ of the specimen and $d$ is the width of the specimen in $\mathrm{m}$. Three specimens were tested for each composition.

To study the fracture toughness, the resistance-curve method was used. Experiments were carried out on single edge notched bend (SENB) [33]; the specimens were molded in metallic molds with a notch to width ratio $\left(\mathrm{a}_{0} / \mathrm{w}\right)$ of 0.4 . The specimens were subjected to three-point bend loading in an electromechanical testing machine UTM7001 Model 4002 (Utest, Ankara, Turkey) as seen in Figure 1. The resistance-curve experiments were carried out on specimens left in the laboratory environment at a temperature of $27^{\circ} \mathrm{C}$ for 7 days, 14 days and 28 days. The specimens were loaded at a ramp rate of $1.2 \mathrm{~N} / \mathrm{s}$ to examine the possible crack propagation; this was achieved with a proscope video monitoring system. The video obtained from the proscope was analyzed with the scientific imaging software "image J 2", which was used to investigate the crack/microstructure interactions that resulted in the resistance-curve behavior. Loading was carried out until the specimens broke into two or more pieces. The critical stress intensity factors were then calculated using the following expression:

$$
\mathrm{K}=\frac{\operatorname{PSf}(\mathrm{a} / \mathrm{w})}{\sqrt{ } B W}
$$

where

$$
\mathrm{f}(\mathrm{a} / \mathrm{w})=\frac{3\left(\frac{\mathrm{a}}{\mathrm{w}}\right)^{1 / 2}\left\{1.99-(\mathrm{a} / \mathrm{w})(1-\mathrm{a} / \mathrm{w})\left(2.15-\frac{3.93 a}{\mathrm{w}}+2.7 \mathrm{a}^{2} / \mathrm{w}^{2}\right)\right\}}{2(1+2 \mathrm{a} / \mathrm{w})\left(1-\frac{\mathrm{a}}{\mathrm{w}}\right)^{1 / 2}}
$$

where $\mathrm{K}$ is the critical stress intensity factor in $\mathrm{MPa} \cdot \mathrm{m} \frac{1}{2}$, a is the crack length in $\mathrm{m}, \mathrm{F}(\mathrm{a} / \mathrm{w})$ is the specimen compliance, $\mathrm{P}$ is the applied load in $\mathrm{N}, \mathrm{S}$ is the span in $\mathrm{mm}, \mathrm{B}$ is the specimen thickness in $\mathrm{mm}$ and $\mathrm{W}$ is the specimen width in $\mathrm{mm}$. SEM was used to examine the crack/microstructure interactions associated with stable crack growth, prior to the onset of catastrophic failure. 


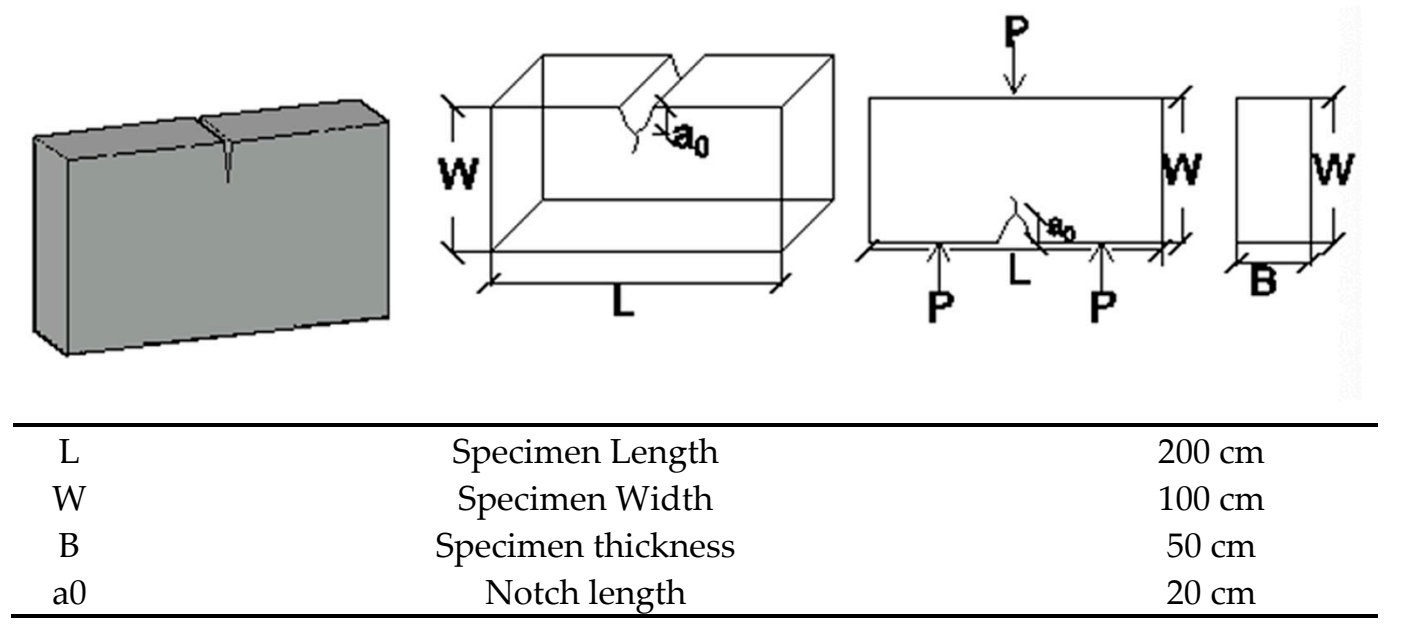

Figure 1. Detailed schematics for single edge notched bend (SENB) specimens.

Data analysis was conducted on the different mechanical properties to analyze the effect of the stabilization variation on the mechanical behavior from the early curing age until 28 days. One-way analysis of variance (ANOVA) tests was used to detect the existence of variations between the population means. The null hypothesis (Ho) suggests that the different curing days do not have any effect on the mechanical properties (fracture toughness, compressive and flexural strength) meaning that the average results for all curing conditions are equal. While the alternative hypothesis (Ha) suggests that at least one average result is different in other terms:

$\mathrm{H}_{0}: \mu_{1}=\mu_{2}=\mu_{3}$ and Ha: at least one average of the mechanical properties is different where $\mu_{1}, \mu_{2}$ and $\mu_{3}$ are population means corresponding to the mechanical properties (compressive-flexural strengths and fracture toughness) at different curing days for the stabilized and unstabilized TMS. A confidence degree of $95 \%$ was selected for this study.

\section{Results and Discussions}

\subsection{Effect of the TMS Partial Replacement on the Microstructural Properties}

\subsubsection{Morphological and Chemical Component Analysis}

SEM Micrographs for the initial TMS presented in Figure 2.

Figure 3 shows heterogeneous microstructures with various particles sizes and shapes. It is also interesting to note that microcracks, highly interconnected particles with some superficial pores, were observed abundantly in the unstabilized samples, whilst they tend to decrease in the stabilized mixtures with Portland cement, as shown.

Presence of new minerals namely $\mathrm{Sr}, \mathrm{Kr}$ and $\mathrm{Ra}$ can be noticed. This can be attributed to the manufacturing process because these minerals do not appear in any other specimens. A possible explanation is that during the specimen's fabrication, the materials have been mistakenly polluted with a foreign material containing these minerals.

The SEM-EDX analysis shows that the TMS is rich in silicate and alumina; these results are similar to the ones obtained from Ajiboye's work. In his work the termite soil was classified as natural pozzolanas [28]. The overall silicate and alumina contents of the TMS/Portland cement mixtures have increased upon the replacement of TMS with Portland cement. The Ca present in the cement reacts with the water and the environing air to form calcium hydroxide $\mathrm{CaO}(\mathrm{s})+\mathrm{H}_{2} \mathrm{O}(\mathrm{l}) \rightarrow \mathrm{Ca}(\mathrm{OH})_{2}$ (s) [10]. The increase in the silicate and alumina content is attributed to the formation of di-calcium and tri-calcium silicates, which imparts strength to the cement. The alumina supplied by the TMS behaves as a flux when mixed in the cement. Furthermore, the iron oxide present in the initial TMS forms tri-calcium alumina-ferrite [42] by reacting with the calcium supplied by the cement, which results in improved strength and hardness. Thus, the TMS provides sources 
of $\mathrm{Si}$ and $\mathrm{Al}_{2} \mathrm{O}_{3}$ for additional hydration reaction with the $\mathrm{Ca}$ apported from the cement to impart the strength of the mixtures.

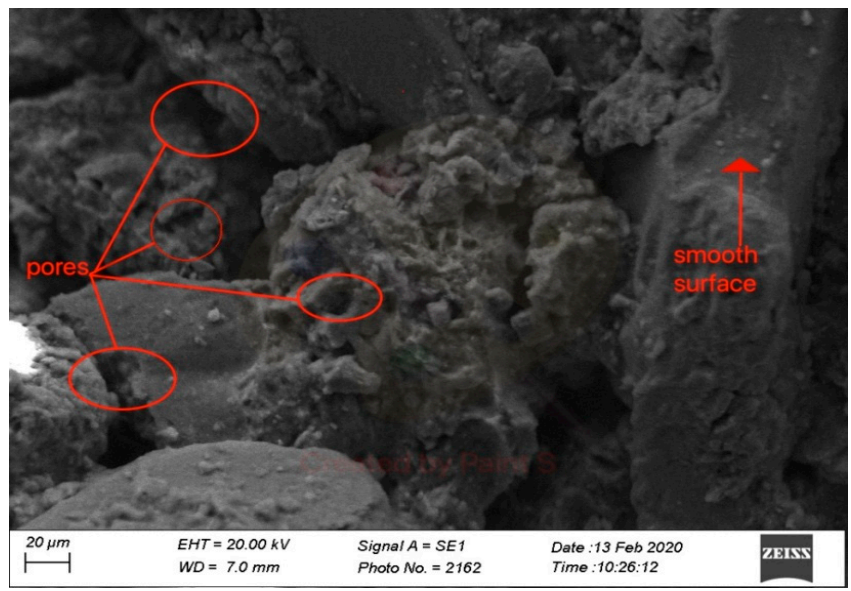

(a)

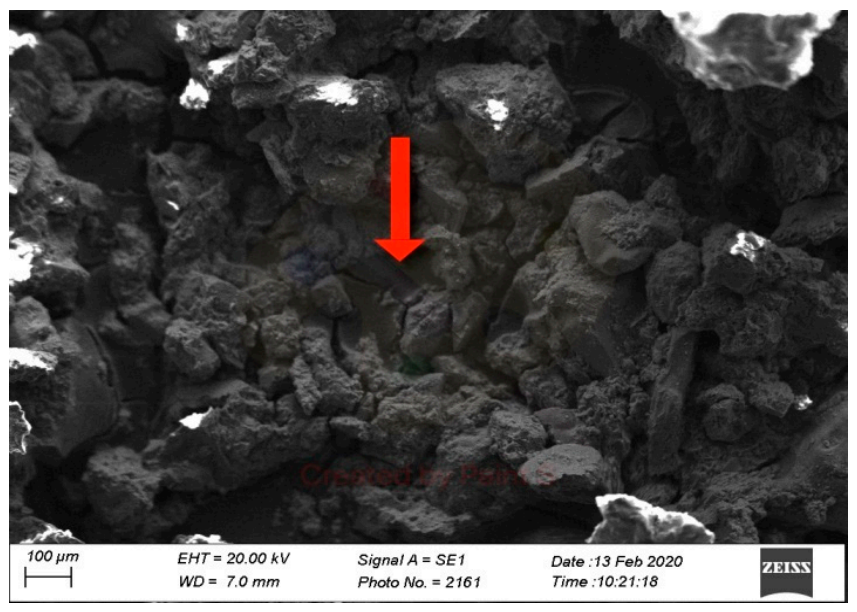

(c)

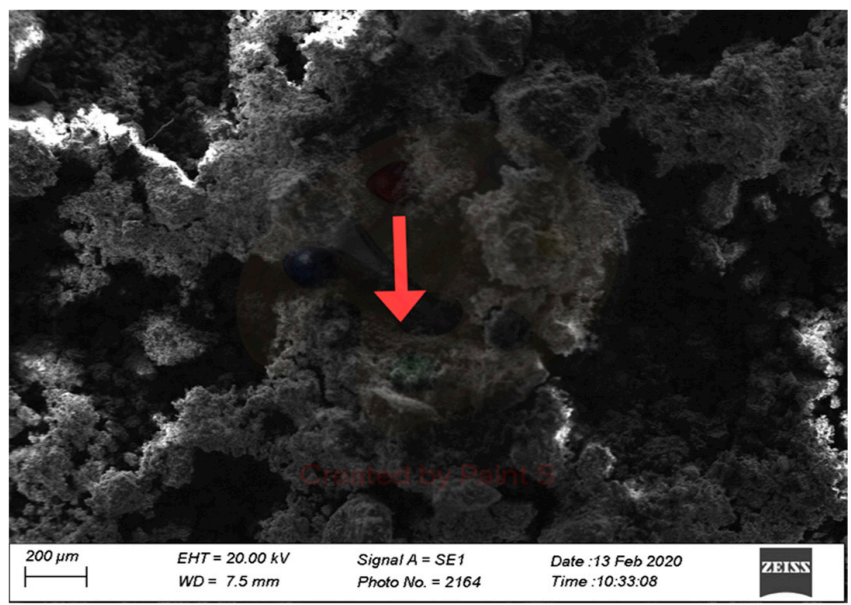

(e)

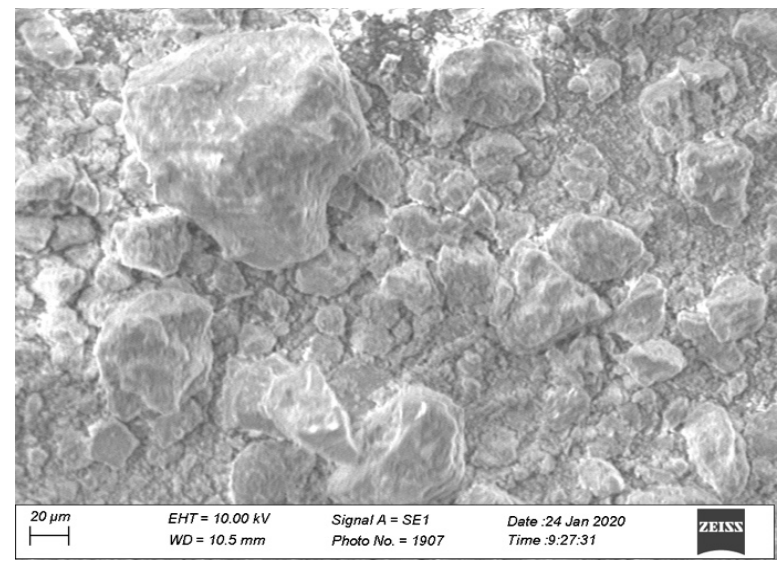

(b)

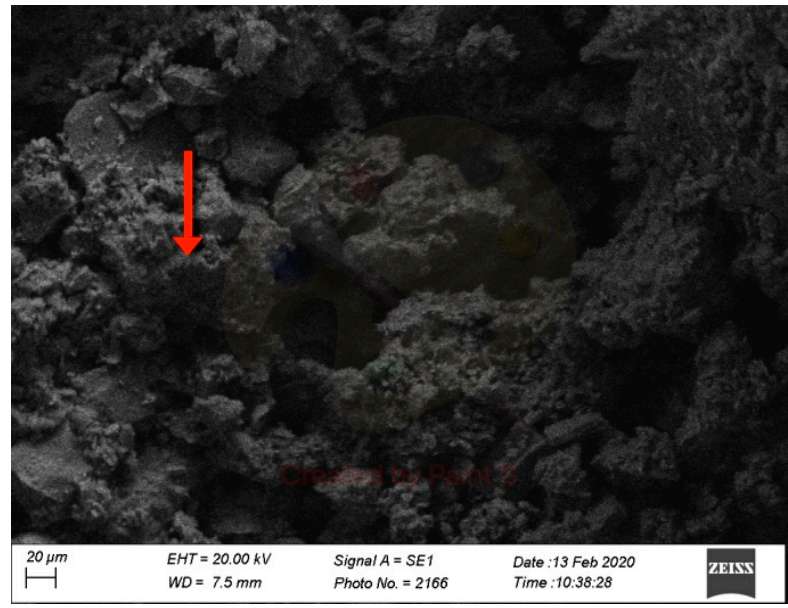

(d)

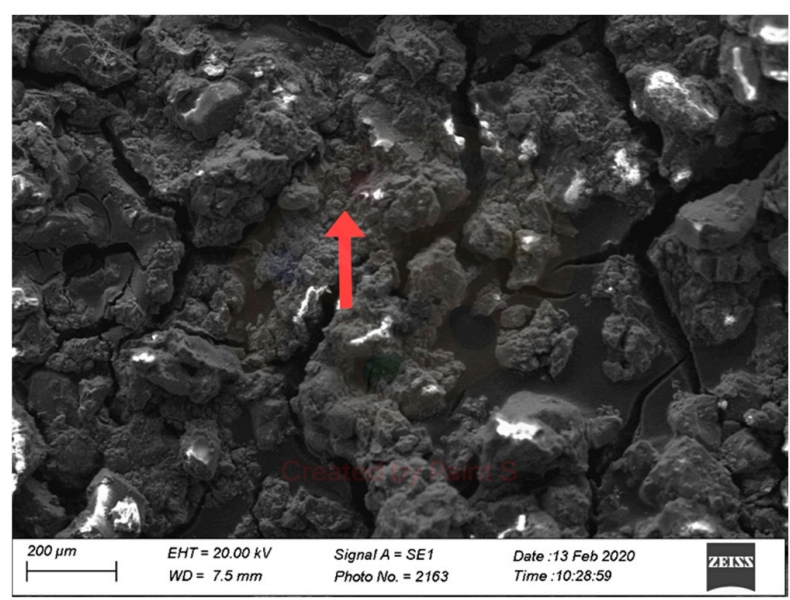

(f)

Figure 2. SEM micrographs of: (a) unstabilised termite mound soil; (b) Ordinary Portland Cement; (c) specimens containing $5 \mathrm{wt} \%$ of stabilisation; (d) specimens containing $10 \mathrm{wt} \%$ of stabilisation; (e) specimens containing $15 \mathrm{wt} \%$ of stabilisation; (f) specimens containing $20 \mathrm{wt} \%$ of stabilisation. 


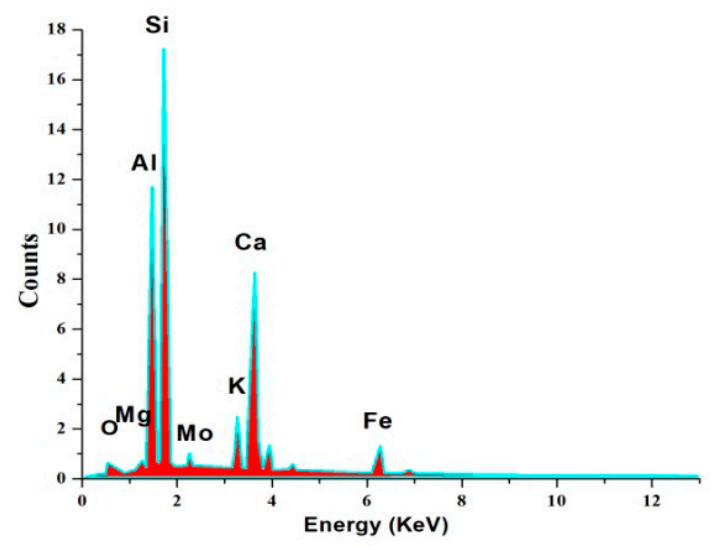

(a)

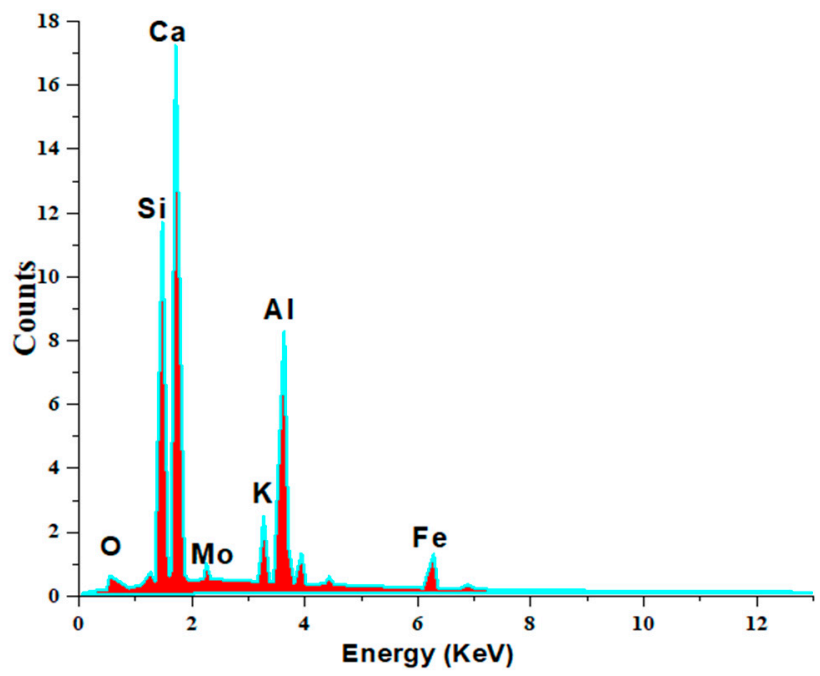

(c)

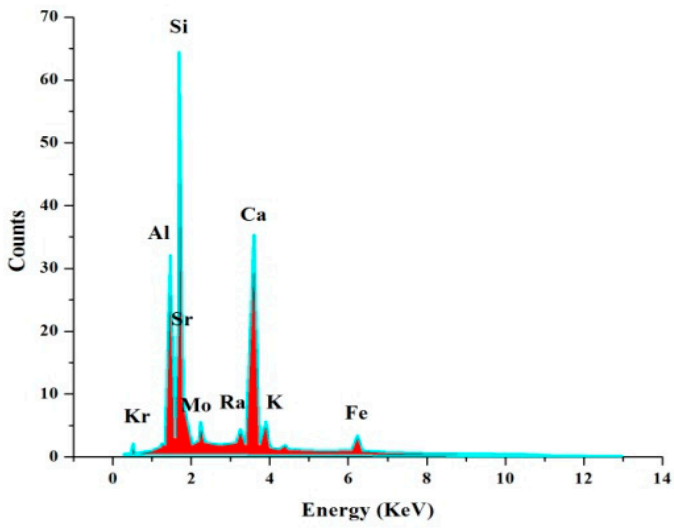

(b)

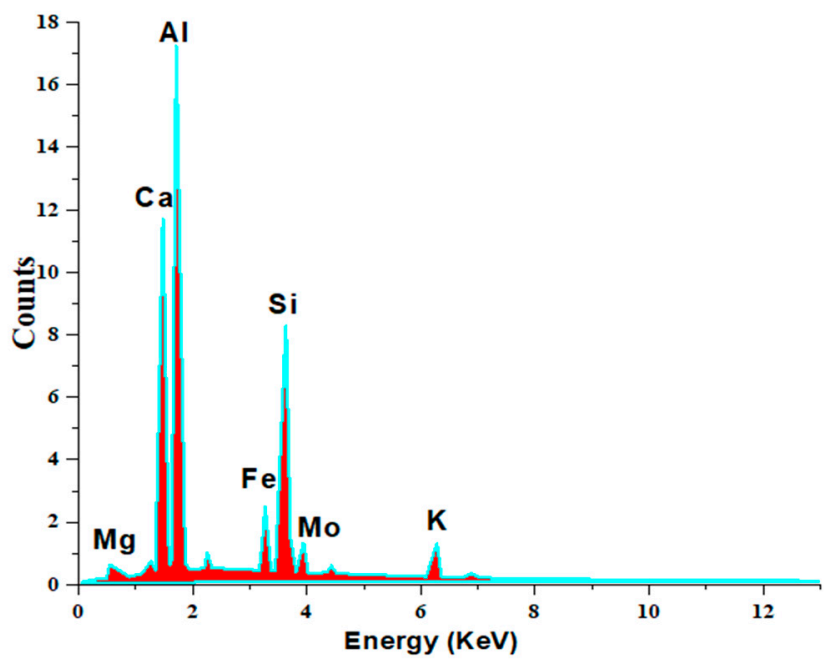

(d)

Figure 3. EDX micrographs of: (a) specimens containing $5 \mathrm{wt} \%$ of stabilisation; (b) specimens containing $10 \mathrm{wt} \%$ of stabilisation; (c) specimens containing $15 \mathrm{wt} \%$ of stabilisation; (d) specimens containing $20 \mathrm{wt} \%$ of stabilisation.

Furthermore, the mineralogical analysis conducted by Faria [43] showed that the predominant clay-mineral is kaolinite, hence the similarities with our present results but with some differences. These differences can be attributed to the variations in the location from where the TMS is collected, because locally available clays are used to construct the termite mounds therefore their composition varies from one location to the other. However, each component plays a role in the particles bonding in terms of chemical reactions and physical structure. In any case, the current EDX results show that the partial replacement of TMS with cement increased the amount of calcium (Ca) considerably. This can explain the increase in strength as the replacement level increases. However, this is true only up to some percent replacement; as the replacement level increases the strength decreases. A possible explanation is that the reactions between the elements from the TMS and cement are no longer contributing to the mixture's mechanical behavior.

\subsubsection{Crystalline Phases Analysis}

The XRD spectra are presented in Figure 4. It presents the mineralogical analysis diffractograms of the specimens at different stabilization levels. From the various graphs it can be concluded that the predominant element is quartz $\left(\mathrm{SiO}_{2}\right)$; this confirms the previous EDX results presented in Figure 3 It is interesting to note that the initial crystalline phases 
observed within the TMS changed considerably after the stabilization. Meanwhile, the change of the peak intensity was not considerable.

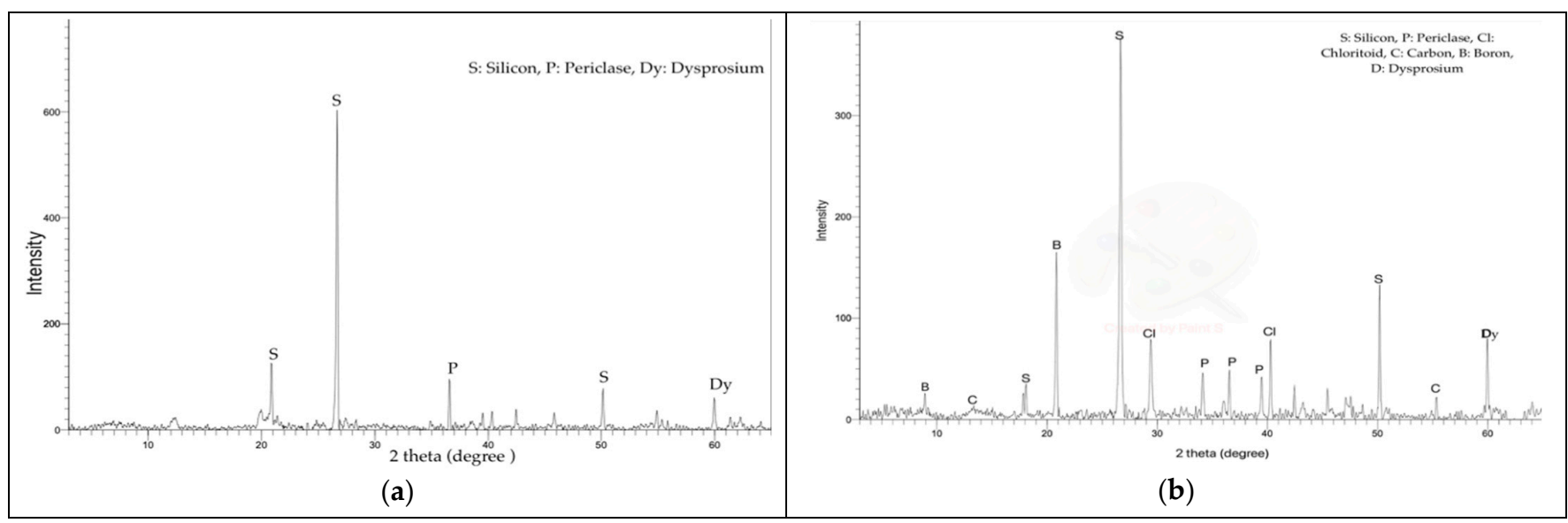

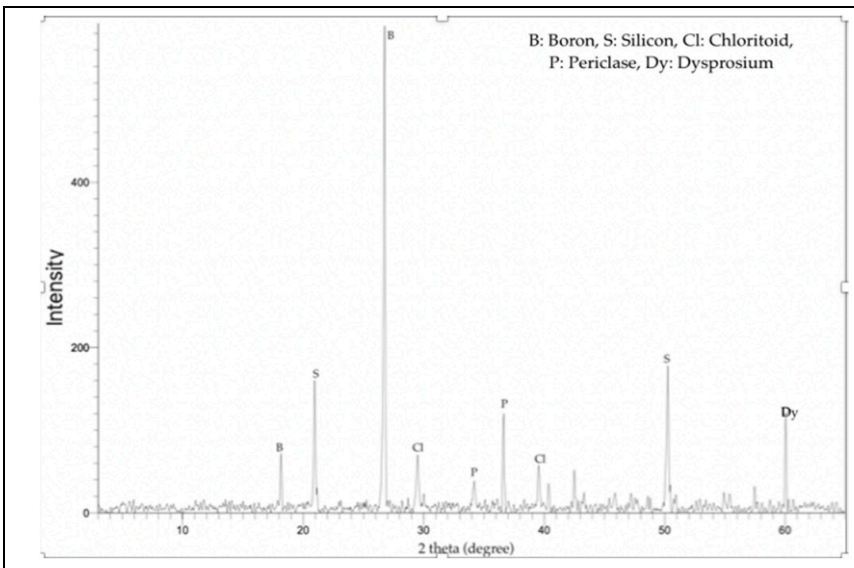

(c)

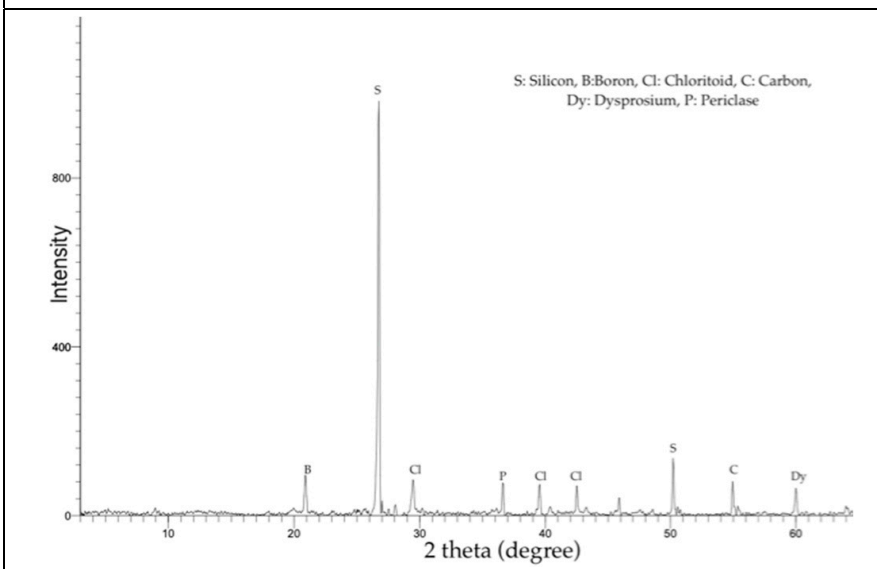

(e)

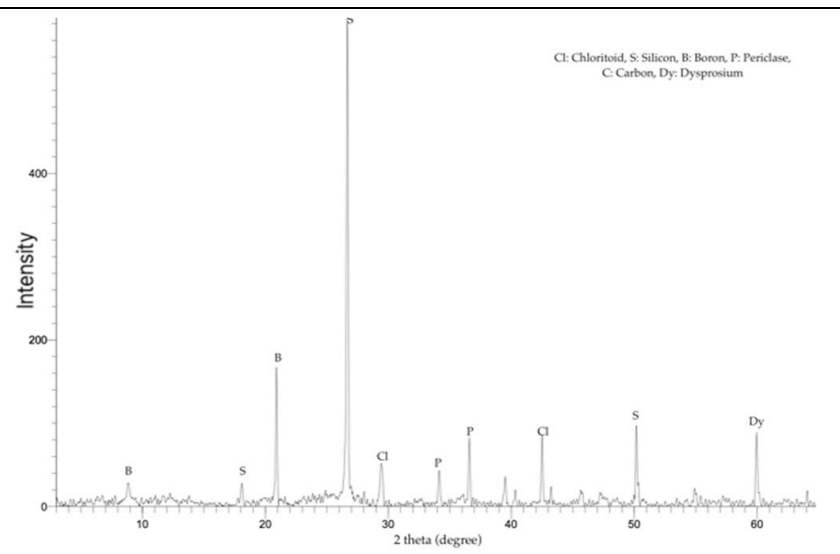

(d)

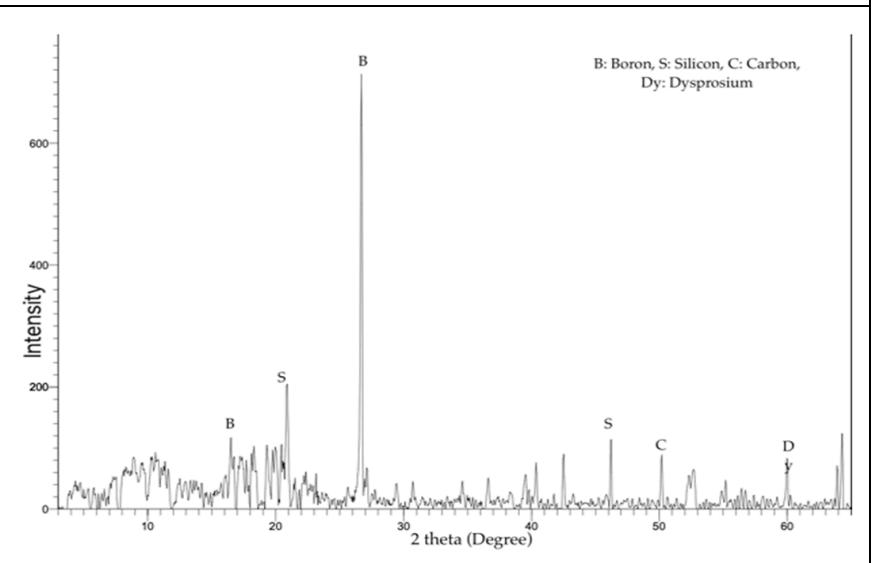

(f)

Figure 4. XRD spectra of: (a) unstabilised termite mound soil; (b) Ordinary Portland Cement; (c) specimens containing $5 \mathrm{wt} \%$ of stabilisation; (d) specimens containing $10 \mathrm{wt} \%$ of stabilisation; (e) specimens containing $15 \mathrm{wt} \%$ of stabilisation; (f) specimens containing $20 \mathrm{wt} \%$ of stabilisation.

However, at 5 and $10 \mathrm{wt} \%$ there was not any change in the present minerals and their peaks remained intact too. Nevertheless, some peaks became slightly stronger in the various stabilization levels showing the formation of cementation compounds as affirmed by the EDX results. These changes observed in the spectra of the mixtures, especially for $2 \theta$ 
values were located at around $0-10^{\circ}$ and $30-40^{\circ}$. These changes can be interpreted by the formation of new phases (chloritoid and carbon were observed in the stabilized specimens while absent in the initial termite mound soil) as a result of the hydration reaction.

\subsubsection{FTIR Characterization}

The results show that the spectra are dominated by $\mathrm{C}-\mathrm{C}-\mathrm{C}$ bending, $\mathrm{O}-\mathrm{H}$ stretchingbending and $\mathrm{O}-\mathrm{Si}-\mathrm{O}$ bending bands. In the stabilized mixtures, these bands remained the same, with some displacement. This can be explained by the evident substitution of the $\mathrm{Si}-\mathrm{O}$ bounds by $\mathrm{Si}-\mathrm{O}-\mathrm{Al}$, resulting in the dissolution of the reactive phases (silicon, aluminum) [42].

The existence of network formation after the stabilization of TMS with Portland cement was displayed after the stabilization. This validates the SEM-EDX results where there was some insignificant formation of new phases, but mostly an increase in the number of existing phases was perceived as shown in Table 2. The stretching and bending vibrational absorption peaks of $\mathrm{O}-\mathrm{H}$ shows the chemical bond of water in the stabilized TMS with cement. The hydration reaction generates calcium hydroxide from the calcium oxide which reacts with the carbon dioxide in the air. However, the carbonation reaction increases the bonding between the soil's particles resulting in compressive strength improvement due to the formation of C-S-H (calcium silicate hydrate) [10]. Figure 5 shows the details of the different absorption bands in the FTIR results.

\subsection{Effect of Cement Stabilization on the Macrostructure (Compressive and Flexural Strengths, Fracture Toughness)}

\subsubsection{Compressive Strength}

The results obtained from the compressive tests are presented in Figure 6a. These show that the compressive strengths increased from the curing age of 7 days to 28 days for all the samples with the exception of the $5 \mathrm{wt} \%$ stabilization. The highest compressive strength obtained in this study was 13.91 MPa at $5 \mathrm{wt} \%$ replacement. Prior work by Elinwa [31] on calcined termite mound soil showed that the highest compressive strength obtained was $25.9 \mathrm{MPa}$ at $10 \%$ replacement. The variation of the results between the previous and present work may be attributed to the effect of calcination in the later work which increased the active elements within the termite mound soil. However, in this current study the highest compressive strength met the minimum compressive strength required by the American Society of Testing Materials (ASTM) for a non-load bearing masonry unit.

Our results also show that the curing duration affected the compressive strengths. As the curing period increases, cementation compounds and reactions such as flocculation and reduction in plasticity may take place affecting the soil's strength from that point on. At $5 \mathrm{wt} \%$ replacement of TMS by cement, higher crystallinity was observed than in the other mixtures; as load increases the particles tend to be denser, which results in filling the pores, subsequently increasing the compressive strength. The increase of compressive strength can also be attributed to the cementitious reaction taking place between the siliceous and aluminous components of the TMS and the calcium from the Portland cement. During the testing, the samples failed due to formation of almost-vertical surface cracks and disintegration of sideways (Figure $6 b, c$ ). This is an indication of the plastic deformation of the samples into a triangle-like shape causing the disintegration of the sides. Regardless of the disintegration of the sides, the central part remained intact although the samples experienced deformation and cracking before failure. The developed cracks were parallel to the loading direction.

\subsubsection{Flexural Strength}

The results for the flexural strength tests are presented in Figure 7. The flexural strength increased proportionally to the curing time; from the early time of 7 days to 24 days, the flexural strength for all the samples increased. The unstabilized specimens and the specimens with $20 \mathrm{wt} \%$ of cement did not display any flexural strength at 7 days. The 
highest flexural strength was $10.25 \mathrm{MPa}$ for $5 \mathrm{wt} \%$ replacement. However, in the study carried out by Elinwa [31] the stabilization of calcined soil and mound clay into cement had a greater effect on the flexural strength and the highest flexural strength was $7.2 \mathrm{MPa}$ for $10 \mathrm{wt} \%$ for 28 days. The differences may be attributed to the soil mineralogy and chemical composition as they are not a "fits all" for all the termite mound soil; it is flexible and mainly dependent on the region where the termite mound is located. The results of the flexural strength followed the direction of the compressive strength; this confirms the relationship between the compressive and tensile strength established by Ajiboye in the case of partial replacement of powdered termite soil in concrete [28]. During the testing, it was observed that the initial crack was generated at the mid-span opposite to the loading plane before failure as the applied load increased. The specimens underwent brittle failure. The tensile strength development also reflects the formation of the products from the hydration process in water over the curing age.

Table 2. Peaks and functional groups present in the various samples. Termite mound soil (TMS), termite mound soil 95\%-cement 5\% and termite mound soil 90\%-cement 10\% (TMS95C5 and TMS90C10), termite mound soil 85\%-cement $15 \%$ and termite mound soil 80\%-cement 20\% (TMS85C15 and TMS80C20).

\begin{tabular}{|c|c|c|c|}
\hline TMS $\left(\mathrm{cm}^{-1}\right)$ & TMS5C95 \& TMS 10 C90 $\left(\mathrm{cm}^{-1}\right)$ & $\begin{array}{c}\text { TMS15C85 \& } \\
\text { TMS } 20 \mathrm{C} 80\left(\mathrm{~cm}^{-1}\right)\end{array}$ & Functional Group \\
\hline $3854,3695,3650,3620$ & $3695,3645,3619$ & $3851,3695,3647,3618$ & O-H stretching \\
\hline 1654 & 1652 & 1652 & $\mathrm{C}=\mathrm{C}$ stretching \\
\hline- & 1418 & 1418 & $\mathrm{CH}_{2} \& \mathrm{CH}_{3}$ bending \\
\hline $1101,1032,1008$ & 1032 & 1101 & $\mathrm{C}-\mathrm{C}-\mathrm{C}$ bending \\
\hline- & 1070 & 1032,1007 & Si-O-Si stretching \\
\hline 913 & 912 & 913 & $\mathrm{C}-\mathrm{H}$ bending \\
\hline 795,694 & 753,694 & 795,694 & $\mathrm{O}-\mathrm{H}$ bending \\
\hline 538,469 & 530,469 & 538,470 & $\mathrm{O}-\mathrm{Si}-\mathrm{O}$ bending \\
\hline
\end{tabular}

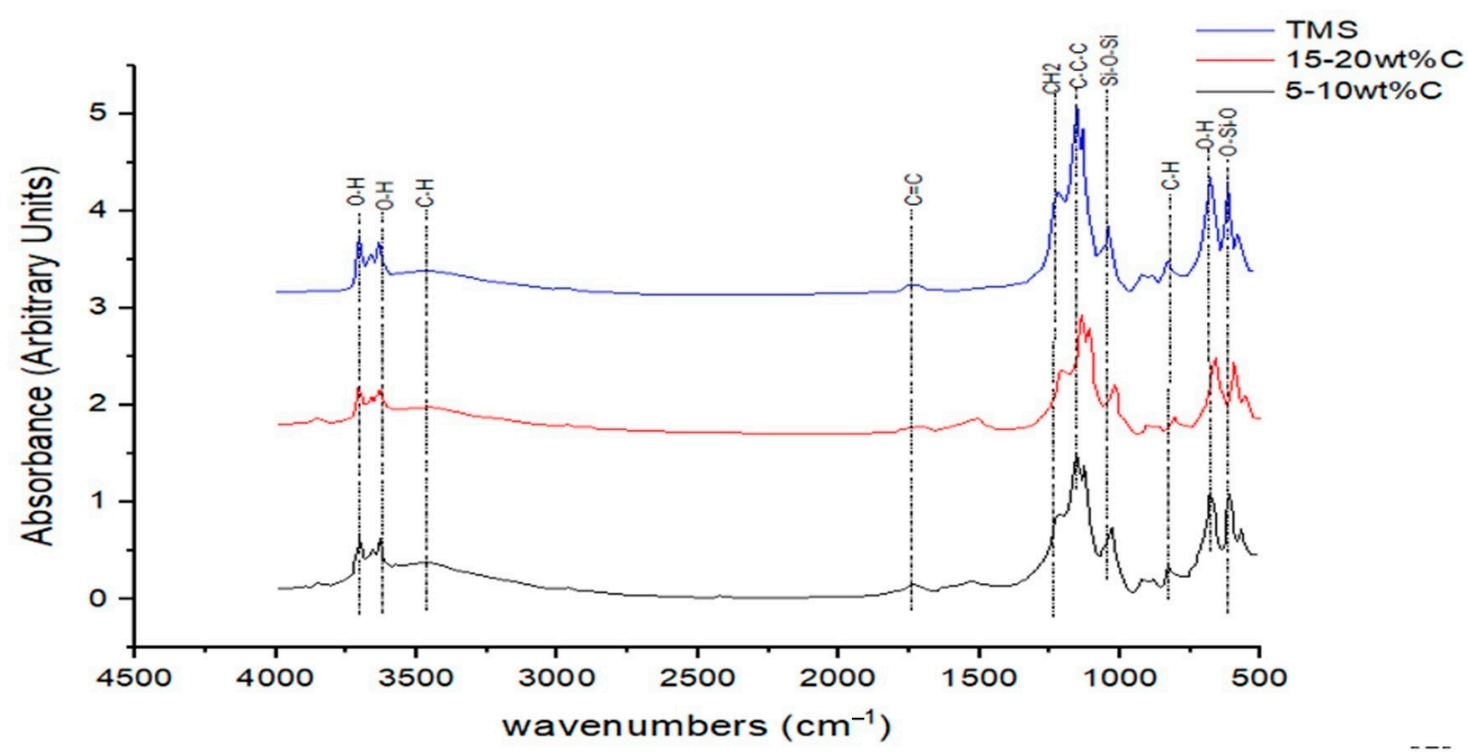

Figure 5. FTIR spectra of the unstabilised termite mound soil and the various stabilisation level (5 wt $\%, 10 \mathrm{wt} \%, 15 \mathrm{wt} \%$ and $20 \mathrm{wt} \%$ ). 


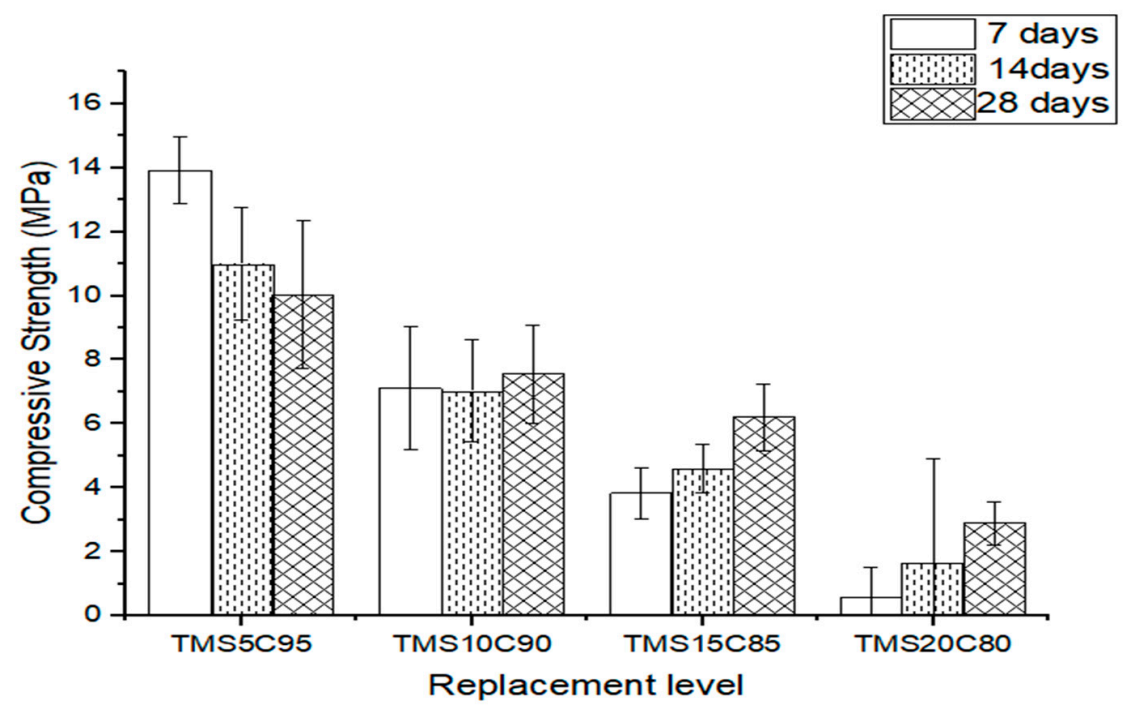

(a)

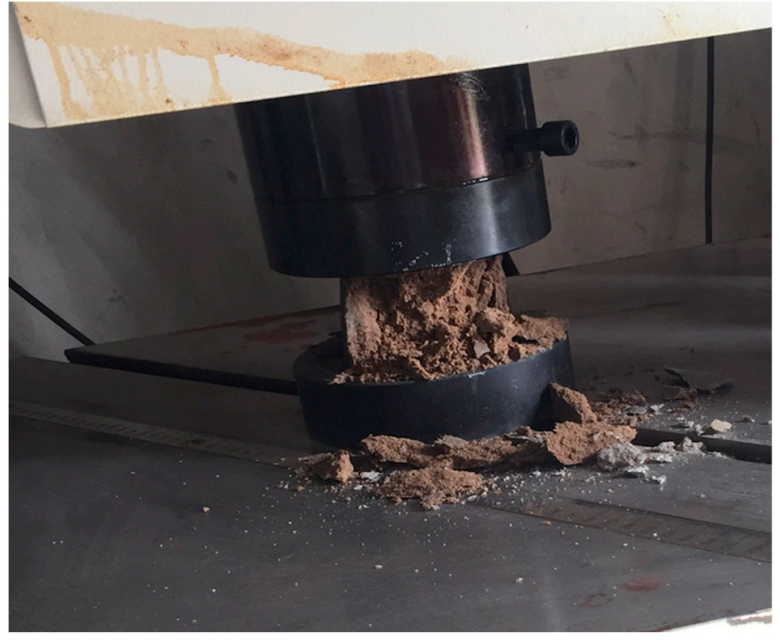

(b)

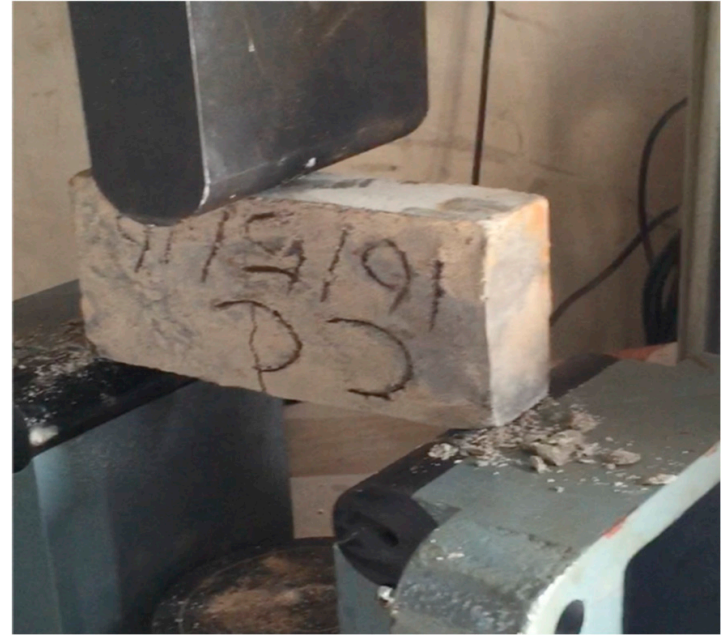

(c)

Figure 6. (a) Compressive strength of the samples at 5\%,10\%, 15\% and 20\% stabilizations designated as TMS5C95, TMS10C90, TMS15C85 and TMS20C80 respectively at the different curing ages (7, 14 and 28 days), (b) specimen failing under compression, (c) specimen's failure under three-point bending testing.

\subsubsection{Fracture Toughness}

The results for the fracture toughness tests are presented in Table 3. In this study, three-point bending tests were carried out on SENB specimens made from stabilized and unstabilized TMS in order to understand the mechanical behavior and crack propagation mechanism in the material to ascertain the cement stabilization's effect on the toughness of the TMS. The resistance curve obtained in Figure 8 gives the main information about initial and final stress intensity factors ( $\mathrm{K}_{0}$ and $\mathrm{K}$ respectively) and the ratio between the crack length and the specimen depth $\left(\mathrm{a}_{0} / \mathrm{W}\right)$ obtained from the R-curves of individual samples tested for the different curing days (7,14 and 28 days). The SENB technique allowed us to plot the R-curve as a function of crack propagation $\Delta \mathrm{a}$; the evolution of cracks follows three stages [44]:

- If $\Delta \mathrm{a}=0$ the crack propagation stops.

- If $0<\Delta \mathrm{a}<\Delta \mathrm{a}_{\mathrm{c}}$ the crack propagation is stable.

- If $\Delta \mathrm{a}>\Delta \mathrm{a}_{\mathrm{c}}$ the crack propagation is unstable. 


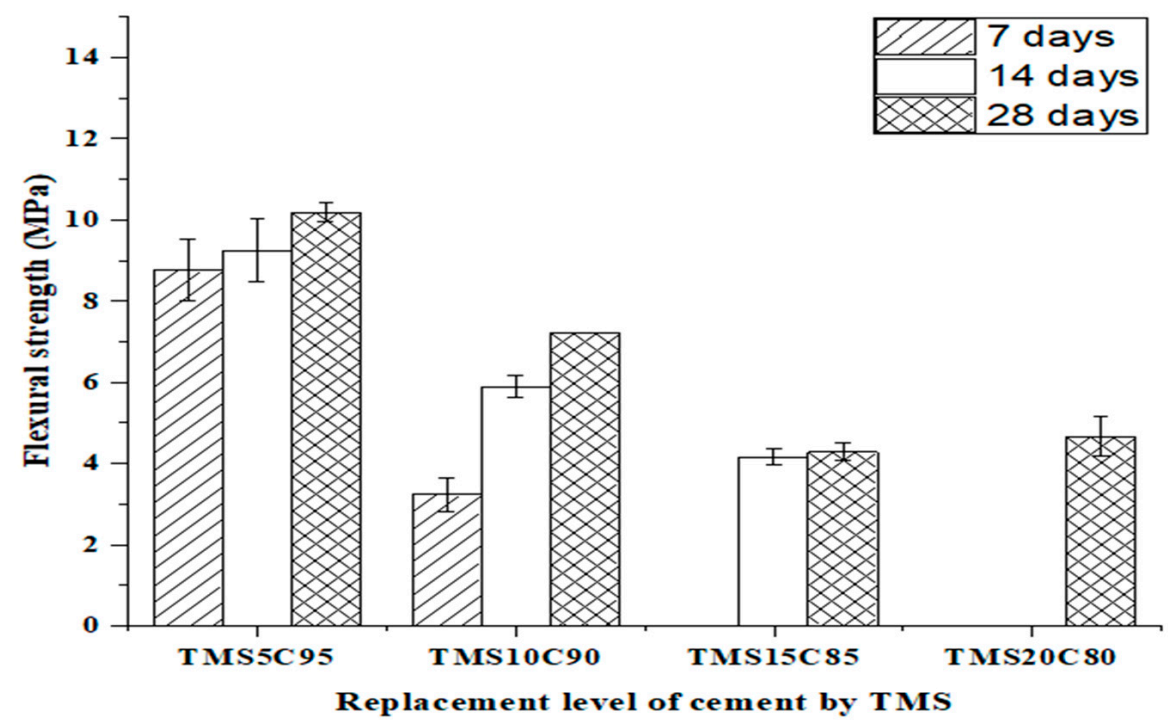

Figure 7. Flexural strength of the various samples with 5, 10, 15 and 20\% stabilizations designated as TMS5C95, TMS10C90, TMS15C85 and TMS20C80 respectively at the curing ages of 7, 14 and 28 days.

Table 3. Information obtained from the R-curves of unstabilized and stabilized TMS.

\begin{tabular}{|c|c|c|c|c|c|c|c|c|c|c|}
\hline \multirow[b]{2}{*}{ Series } & \multirow[b]{2}{*}{ Samples } & \multicolumn{3}{|c|}{7 Days } & \multicolumn{3}{|c|}{14 Days } & \multicolumn{3}{|c|}{28 Days } \\
\hline & & $\begin{array}{c}\mathrm{K} \\
\left(\mathrm{MPa} \cdot \mathrm{m}^{\frac{1}{2}}\right)\end{array}$ & $a / W$ & $\begin{array}{c}P \text { max } \\
\text { Load (KN) }\end{array}$ & $\begin{array}{c}\mathrm{K} \\
\left(\mathrm{MPa} \cdot \mathrm{m}^{\frac{1}{2}}\right)\end{array}$ & $a / W$ & $\begin{array}{c}P \text { max } \\
\text { Load (KN) }\end{array}$ & $\begin{array}{c}\mathrm{K} \\
\left(\mathrm{MPa} \cdot \mathrm{m}^{\frac{1}{2}}\right)\end{array}$ & $a / W$ & $\begin{array}{c}P \text { max } \\
\text { Load (KN) }\end{array}$ \\
\hline \multirow[t]{5}{*}{ Stabilized TMS } & S1 & 0.0003 & 0.4 & 0.0001 & 0.0013 & 0.4 & 0.0005 & 0.00117 & 0.4 & 0.000451 \\
\hline & S2 & 0.0007 & 0.5 & 0.00025 & 0.0021 & 0.5 & 0.00069 & 0.00148 & 0.5 & 0.000506 \\
\hline & S3 & 0.0009 & 0.6 & 0.00027 & 0.0026 & 0.55 & 0.00075 & 0.00254 & 0.55 & 0.000796 \\
\hline & S4 & 0.0012 & 0.7 & 0.00032 & 0.0037 & 0.6 & 0.000975 & 0.00321 & 0.6 & 0.00094 \\
\hline & S5 & - & - & - & 0.0040 & 0.65 & 0.000998 & 0.00352 & 0.65 & 0.000956 \\
\hline \multirow[t]{3}{*}{ Unstabilized TMS } & U2 & 0 & 0.4 & 0 & 0 & 0.4 & 0 & 0 & 0.4 & 0 \\
\hline & U3 & 0 & 0.5 & 0 & 0 & 0.65 & 0 & 0 & 0.55 & 0 \\
\hline & $\mathrm{U} 4$ & 0 & 0.6 & 0 & 0 & 0.7 & 0 & 0 & 0.6 & 0 \\
\hline
\end{tabular}

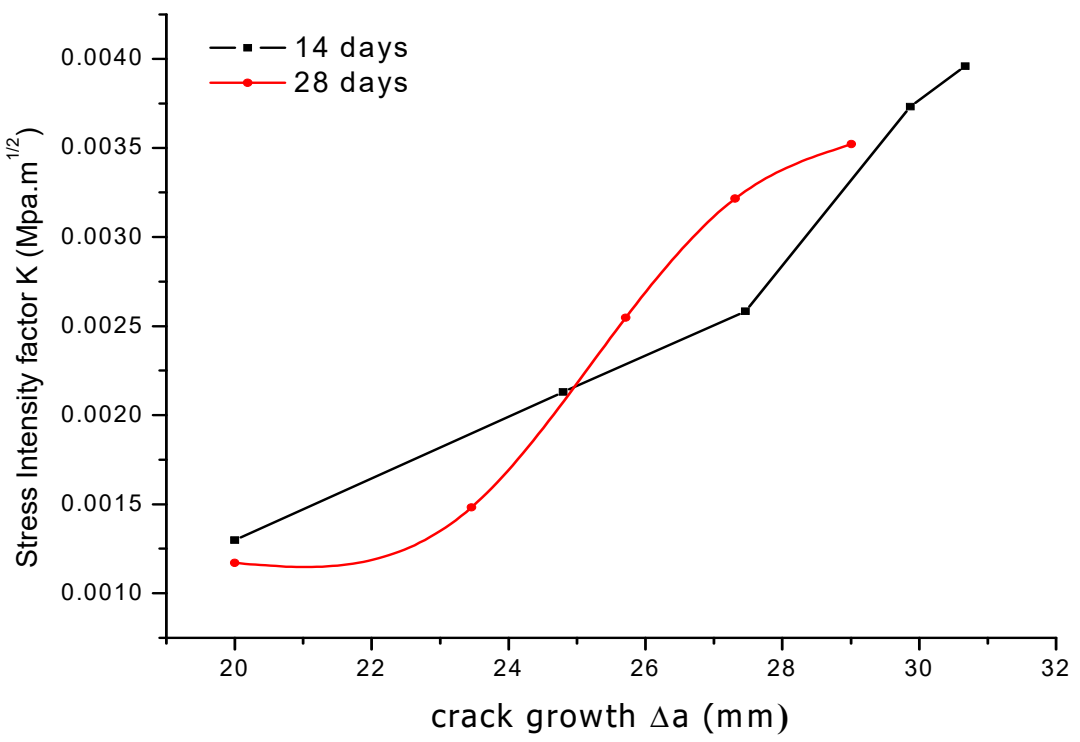

Figure 8. Fracture toughness of the $5 \mathrm{wt} \%$ stabilization after curing for 14 and 28 days. 
It can be observed that the initial crack was generated at the notch, which is at the opposite loading plane of the sample, and it propagates until failure occurs. The stabilized TMS displayed crack propagation mechanisms comporting stable propagation and unstable propagation. At the beginning of the loading, the crack propagation was stable, while it changed to unstable propagation as the loading increased. However, the stable propagation mechanism was considerably more important than the unstable propagation. At the early curing age of 7 days the samples did not show any resistance as they failed at loading of $0 \mathrm{KN}$. Nevertheless, the samples exhibited some toughness at the late curing age of 28 days: a stress intensity factor of $0.00352 \mathrm{MPa} \mathrm{m}^{\frac{1}{2}}$ and $\mathrm{a} / \mathrm{W}=0.65$. The specimens are expected to acquire more toughness over a long curing period. The unstabilized TMS showed no toughness for all the curing days, although the crack propagation mechanism was stable. The unstabilized TMS specimens contained remarkable surface cracks; these surface cracks give rise to the stable growth.

\subsubsection{Statistical Analysis of the Mechanical Properties}

From the statistical analysis of the mechanical properties, it is observed that the unstabilized and stabilized TMS had no significant difference in the means of compressive strength for all curing days. At the $95 \%$ confidence level, the means of the flexural strength at 7, 14 and 28 days of curing are not significantly different for the stabilized TMS, while for the unstabilized TMS, the means of flexural strength were significantly different for all curing ages. Finally, for the fracture toughness, the statistical analysis showed a significant difference in the stress intensity factor over the crack growth for the stabilized TMS for all the curing days.

\section{Conclusions}

This paper presented the experimental investigation of the strengths (compressive and flexural) and fracture toughness of unstabilized and stabilized TMS. Indeed, the utilization of termite hill soil is aimed to produce eco-friendly materials in constructionrelated fields to address the problem of housing in the central African region, precisely in Chad. TMS stabilization with cement was used with the aim of obtaining an easily replicable engineering technique for that region, where termite hills are very abundant but considered as natural waste. In fact, the stabilization of TMS was done by replacing partially the TMS (5 wt \%, $10 \mathrm{wt} \%, 15 \mathrm{wt} \%$ and $20 \mathrm{wt} \%$ ) using Portland cement to ascertain the effect of the cement as stabilizer and also to reduce the amount of cement required in construction. This implies a reduction of the total housing cost. Salient conclusions deduced from the study are presented below.

- The stabilization of TMS with 5\% Portland cement showed good interactions between the two phases (cement and TMS) from the microstructural level to the macrostructures (mechanical behavior). Initially, the unstabilized TMS displayed some pozzolanic properties, thus the partial replacement by cement demonstrated very good bonding in addition to the hydration process products. Thus, the stabilization enhanced the TMS strengths due to the development of a greater bond between the soil and cements' particles for all the replacement levels.

- The highest compressive strength was obtained for $5 \mathrm{wt} \%$ stabilization. That compressive strength development is high due to the cement stabilization through the formation of a new strong network.

- The flexural strength development followed the compressive strength direction. However, the highest flexural strength observed was $10.25 \mathrm{MPa}$ at 28 days for $5 \mathrm{wt} \%$ stabilization. This flexural strength is significantly greater than the results obtained from the calcined termite mound soil [31];

- The various stabilization levels $(10,15$ and $20 \mathrm{wt} \%)$ did not display any toughness to fracture. Only the $5 \mathrm{wt} \%$ displayed some toughness despite its characteristics of crack propagation (stable and unstable). It exhibited the highest stress intensity factor 3.52 $\mathrm{kPa} \cdot \mathrm{m}^{\frac{1}{2}}$ at $\mathrm{a} / \mathrm{W}=0.65$ at 28 days. 
This study shows that termite mound soil can be efficiently engineered into a sustainable construction material via stabilization technology. In any case, this study constitutes the first investigation of the crack propagation mechanism of termite mound soil. The results of this study are a solution among many others to the housing problem in Chad and in SSA. They are a solution in the sense that the results of this study can be produced at industrial scale in restrained regions without high demand of manufacturing instruments and materials. Additionally, the use of uncalcined termite mound soil is aimed to reduce the carbon footprint during manufacturing. Indeed, the main material is locally available, renewable and its acquisition is free without any cost. For future work, termite mound soil can be used in the production of bio-composites with natural or synthetic fibers.

Author Contributions: Conceptualization: A.A.M., N.L.B., O.A. Methodology: A.A.M., H.S.J., W.O.S. Writing-original draft preparation: A.A.M., N.L.B., O.A., P.A.O. Writing-review and editing: A.A.M., N.L.B., O.A., P.A.O. Supervision; P.A.O., H.S.J., W.O.S. Funding acquisition: H.S.J., W.O.S. All authors have read and agreed to the published version of the manuscript.

Funding: This research was funded by the Pan African Materials Institute (PAMI) under the World Bank, African Centers of Excellence (ACE) program hosted by the African University of Science and Technology (AUST). The grant number is AUST/PAMI/2015/5415-NG.

Data Availability Statement: The data presented in this study are available on request from the corresponding author after obtaining permission of authorized person.

Conflicts of Interest: The authors declare no conflict of interest.

\section{References}

1. Karim, M.R.; Hossain, M.; Khan, M.N.N.; Zain, M.F.M.; Jamil, M.; Lai, F.C. On the Utilization of Pozzolanic Wastes as an Alternative Resource of Cement. Materials 2014, 7, 7809-7827. [CrossRef] [PubMed]

2. Kim, T.; Tae, S.; Chae, C.U.; Lee, K. Proposal for the Evaluation of Eco-Efficient Concrete. Sustainability 2016, 8, 705. [CrossRef]

3. Zhang, H.; Wang, S.; Hao, J.; Wang, X.; Wang, S.; Chai, F.; Li, M. Air pollution and control action in Beijing. J. Clean. Prod. 2016, 112, 1519-1527. [CrossRef]

4. Pode, R. Potential applications of rice husk ash waste from rice husk biomass power plant. Renew. Sustain. Energy Rev. 2016, 53, 1468-1485. [CrossRef]

5. Bediako, M. Pozzolanic potentials and hydration behavior of ground waste clay brick obtained from clamp-firing technology. Case Stud. Constr. Mater. 2018, 8, 1-7. [CrossRef]

6. Mo, K.H.; Alengaram, U.J.; Jumaat, M.Z.; Yap, S.P.; Lee, S.C. Green concrete partially comprised of farming waste residues: A review. J. Clean. Prod. 2016, 117, 122-138. [CrossRef]

7. Memon, S.A.; Wahid, I.; Khan, M.K.; Tanoli, M.A.; Bimaganbetova, M. Environmentally Friendly Utilization of Wheat Straw Ash in Cement-Based Composites. Sustainability 2018, 10, 1322. [CrossRef]

8. Xu, W.; Lo, Y.T.; Ouyang, D.; Memon, S.A.; Xing, F.; Wang, W.; Yuan, X. Effect of rice husk ash fineness on porosity and hydration reaction of blended cement paste. Constr. Build. Mater. 2015, 89, 90-101. [CrossRef]

9. Olotuah, A.O. Recourse to earth for low-cost housing in Nigeria. Build. Environ. 2002, 37, 123-129. [CrossRef]

10. Obianyo, I.I.; Onwualu, A.P.; Soboyejo, A.B. Mechanical behaviour of lateritic soil stabilized with bone ash and hydrated lime for sustainable building applications. Case Stud. Constr. Mater. 2020, 12, e00331. [CrossRef]

11. Memon, S.A.; Khan, M.K. Ash blended cement composites: Eco-friendly and sustainable option for utilization of corncob ash. J. Clean. Prod. 2018, 175, 442-455. [CrossRef]

12. Sadh, P.K.; Duhan, S.; Duhan, J.S. Agro-industrial wastes and their utilization using solid state fermentation: A review. Bioresour. Bioprocess. 2018, 5, 1. [CrossRef]

13. Olorunnisola, A.O. Development of Sustainable Building Materials from Agro- Industrial Wastes in Nigeria. In Sustainable Construction and Building Materials; IntechOpen: London, UK, 2019.

14. Ojo, E.B.; Bello, K.O.; Ngasoh, O.F.; Stanislas, T.T.; Mustapha, K.; Savastano, H.; Soboyejo, W. Mechanical performance of fiber-reinforced alkali activated un-calcined earth-based composites. Constr. Build. Mater. 2020, 247, 118588. [CrossRef]

15. Ojo, E.B.; Mustapha, K.; Teixeira, R.S.; Savastano, H. Development of unfired earthen building materials using muscovite rich soils and alkali activators. Case Stud. Constr. Mater. 2019, 11, e00262. [CrossRef]

16. Park, J.; Tae, S.; Kim, T. Life cycle CO2 assessment of concrete by compressive strength on construction site in Korea. Renew. Sustain. Energy Rev. 2012, 16, 2940-2946. [CrossRef]

17. Bahurudeen, A.; Santhanam, M. Influence of different processing methods on the pozzolanic performance of sugarcane bagasse ash. Cem. Concr. Compos. 2015, 56, 32-45. [CrossRef]

18. Daniel, K. Make cities and human settlements inclusive, safe, resilient and sustainable. UN Chron. 2015, 51, 26-27. [CrossRef] 
19. Onyelowe, K.; Van, D.B.; Igboayaka, C.; Orji, F.; Ugwuanyi, H. Rheology of mechanical properties of soft soil and stabilization protocols in the developing countries-Nigeria. Mater. Sci. Energy Technol. 2019, 2, 8-14. [CrossRef]

20. H. Foundation. Chad Economy. Available online: https://www.heritage.org/index/country/chad. (accessed on 15 December 2020).

21. Idris, M.K.; Boukar, M.M.; Adeshina, S.A. Analysis of Bad Roads Using Smart phone. In Proceedings of the 15th International Conference on Electronics, Computer and Computation (ICECCO), Abuja, Nigeria, 12 December 2019; pp. 1-4. [CrossRef]

22. Indicateurs Économiques et Sociodémographiques. Available online: https://fr.countryeconomy.com/pays/tchadHighlight. (accessed on 22 October 2020).

23. World Bank in Chad-Overview. Available online: https://www.worldbank.org/en/country/chad/overview (accessed on 12 October 2020).

24. Ministère des Infrastructures et des Transports. Available online: http://www.mit-tchad.org/index.php/fr/. (accessed on 15 October 2020).

25. Awotera, P.O.; Akinwumi, I.I. Compressive Strength Development for Cement, Lime and Termite-hill Stabilised Lateritic Bricks. Int. J. Eng. Sci. 2014, 3, 37-43.

26. Mustapha, K.; Annan, E.; Azeko, S.T.; Kana, M.G.Z.; Soboyejo, W. Strength and fracture toughness of earth-based natural fiber-reinforced composites. J. Compos. Mater. 2015, 50, 1145-1160. [CrossRef]

27. Azeko, S.T.; Mustapha, K.; Annan, E.; Odusanya, O.S.; Soboyejo, W. Recycling of Polyethylene into Strong and Tough Earth-Based Composite Building Materials. J. Mater. Civ. Eng. 2016, 28, 04015104. [CrossRef]

28. Fapohunda, C.A.; Daramola, D.D. Experimental study of some structural properties of concrete with fine aggregates replaced partially by pulverized termite mound (PTM). J. King Saud Univ. Eng. Sci. 2020, 32, 484-490. [CrossRef]

29. Gandia, R.M.; Corrêa, A.A.R.; Gomes, F.C.; Marin, D.B.; Santana, L.S. PHYSICAL, MECHANICAL AND THERMAL BEHAVIOR OF ADOBE STABILIZED WITH “SYNTHETIC TERMITE SALIVA”. Engenharia Agrícola 2019, 39, 139-149. [CrossRef]

30. Mujinya, B.; Mees, F.; Erens, H.; Dumon, M.; Baert, G.; Boeckx, P.; Ngongo, M.; Van Ranst, E. Clay composition and properties in termite mounds of the Lubumbashi area, D.R. Congo. Geoderma 2013, 192, 304-315. [CrossRef]

31. Elinwa, A. Experimental characterization of Portland cement-calcined soldier-ant mound clay cement mortar and concrete. Constr. Build. Mater. 2006, 20, 754-760. [CrossRef]

32. Omofunmi, O.E.; Oladipo, O.L. Assessment of termite mound additive on soil physical characteristics. Agric. Eng. Int. CIGR J. 2018, 20, 40-46.

33. Sarcinelli, T.S.; Schaefer, C.E.G.; Lynch, L.D.S.; Arato, H.D.; Viana, J.H.M.; Filho, M.R.D.A.; Gonçalves, T.T. Chemical, physical and micromorphological properties of termite mounds and adjacent soils along a toposequence in Zona da Mata, Minas Gerais State, Brazil. Catena 2009, 76, 107-113. [CrossRef]

34. Corrêa, A.A.; Bufalino, L.; Protásio, T.D.P.; Ribeiro, M.X.; Wisky, D.; Mendes, L.M. Evaluation of Mechanical Properties of Adobe Chemically Stabilized with "Synthetic Termite Saliva". Key Eng. Mater. 2014, 600, 150-155. [CrossRef]

35. Kandasami, R.K.; Borges, R.M.; Murthy, T.G. Effect of biocementation on the strength and stability of termite mounds. Environ. Geotech. 2016, 3, 99-113. [CrossRef]

36. Legget, R.F. American Society for Testing and Materials. Nat. Cell Biol. 1964, 203, 565-568. [CrossRef]

37. Jean-Pierre, B.; Moise, A.A.A.; Mauricette, S.-W.O.-N.; Sylvain, T.C.; Philippe, K.K.; Yao, T.; Ahouda, Y. Spatial distribution and density of termite mounds in a protected habitat in the south of cote d'ivoire: Case of national floristic center (cnf) of ufhb of Abidjan. Eur. Sci. J. 2015, 11, 241-259.

38. Firoozi, A.A.; Olgun, C.G.; Baghini, M.S. Fundamentals of soil stabilization. Int. J. Geo Eng. 2017, 8, 26. [CrossRef]

39. British Standard Methods of Testing for Soil for Civil Engineering Processes; British Standards Institution: London, UK, 1990; BS 1337: Part 2.

40. ASTM. ASTM D854 Standard Test Methods for Specific Gravity of Soil Solids by Water Pycnometer; ASTM Int.: Washington, DC, USA, 2002; Volume 4, pp. 1-9.

41. ASTM. ASTM C 150 Standard Specification for Portland Cement; ASTM Int.: Washington, DC, USA, 2005. [CrossRef]

42. Ayobami, A.B.; Bamidele, A.; Oluwanifemi, A. Influence of water repellent chemical additive and different curing regimes on dimensional stability and strength of earth bricks from termite mound-clay. Heliyon 2019, 5, 01182. [CrossRef]

43. Faria, O.B.; Battistelle, R.A.G.; Neves, C. Influence of the addition of "synthetic termite saliva" in the compressive strength and water absorption of compacted soil-cement. Ambiente Construído 2016, 16, 127-136. [CrossRef]

44. Soboyejo, W. Mechanical Properties of Engineered Materials; CRC Press: Boca Raton, FL, USA, 2002. 